\title{
Stable hours and varied work as aids to efficiency
}

ROBERT T. WILKINSON and ROBERT S. EDWARDS, Applied Psychology Research Unit. 15 Chaucer Road. Cambridge. England

Stabilization of shift times and rotation of jobs within a shift has cnabled a 2-man system of continuous manning to outperform a 3-man arrangement which lacked these features. In vigilance-type tasks calling for sustained attention it is probably the job rotation which is important; in mare intense cognitive tasks such as complex decision-taking it may be the stabilization of daily shift times which confers the advantage. with job rotation doing more harm than good.

An experiment has been carried out to compare the efficiency of two systems for manning a post continuously $24 \mathrm{~h}$ a day. The conventional naval system employs three men (or watches) for each position. To share night duty more equally this system cycles at roughly a 20 -h period, so that the men work different times on successive days. Also it is usual for them to work on the same task throughout each duty period or "shift" of 4 , or occasionally $2 \mathrm{~h}$. This system has been compared with a proposed one requiring only two men per post, working $12 \mathrm{~h}$ a day instead of 8 . In an attempt to offset this disadvantage the proposed system has included two features in marked contrast to the three-man system described above: (a) the two-man system cycles in circadian fashion at a $24 \mathrm{~h}$ interval so that a given man always works at the same time of day or night. (2) During each shift the men alternate work on three tasks instead of workins on one throughout.

$$
\text { METHOD }
$$

Seventeen enlisted men aged between 18 and 30 years acted as Ss. For 12 days they followed the work schedules as shown along the abscisa of Fis. 1. Six Ss worked the three-man system, six more the predominantly daytime half of the two-man system (two-man/days), and five Ss the mainly night time half of the two-man system (two-man/nights). Sublingual measures of body temperature were taken at 2- to 4 -h intervals during the waking periods of the day or night.

The work was organized in sessions of 53-min duration with pauses between each test of about $5 \mathrm{~min}$ for changeover or, occasionally, $11 \mathrm{~min}$ for light refreshment. Each session was devoted to one of three tests: In Vigilance Ss listened to 1/2-sec tones coming continuously at 3-sec intervals. The basic task was to detect the occasional tone which was slightly shorter than the rest. There were only 12 of these "signals" during a 53-min session and their occurrence was spaced irregularly in time. Adding required Ss to add columns and rows of two-digit numbers, correcting their own errors as indicated by $\mathrm{E}$. The score was the number of correct additions completed. Decision-raking required $S$ s to serve a symbolic queue of "customers" in limited time. This test was a development of one by Shaffer (1965) designed to be roughly analogous to traffic control at an airport or road junction: "Customers" varied in how long they occupied the server and how long they could wait before passing out of the queue unserved. The latter outcome could be avoided at extra cost by calling in another server. Two scores were taken: (1) Misses (customers passing unserved) and (2) a Cost Index corresponding to the number of times extra servers had to be called in to avoid Misses. A fuller description is given by Wilkinson (1964).

A further system variable in this experiment was the way in which the tasks were distributed from shift to shift and also across the 53-min sessions within each shift. In the three-man system Ss worked on the same task in all 53-min sessions of any shift and changed tasks from shift to shift, so that at the end of 12 days each task had received equal hours of work. In the two-man system Ss changed tasks within each shift, i.e., from one $53-\mathrm{min}$ session to the next. Again equal time was spent on each task over the whole 12 days.

\section{RESULTS}

Table 1 shows: (1) average level of performance in the first and last 3-day periods of the 12-day routine; (2) an index of change in performance from first to last three days. On two counts the two-man system was superior to the three-man: overall performance on both the first and last three days in Vigilance, and maintenance of performance level from first to last three days in Decision-taking (Cost Index). On one count the three-man system was better. that of performance level (cost) in Decision-taking on the first three days only. Thus on balance the two-man system was superior to that using three men.

Figure I shows curves of sublingual body temperature during the first and last three-day periods. In the two-man/night routine, where the men worked $0000-0700 \mathrm{~h}$ and 1200-1700 $\mathrm{h}$ each day, body temperature showed considerable adaptation by the last three days. The normal fall from midday to the night time measurement points of 2300,0300 , and $0500 \mathrm{~h}$ was reduced in all five Ss $(\mathrm{p}<.05$, one-tail Sign Test). There was no sign of a similar adaptation in the three-man system, where work was carried out at all times of the day and night, or in the two-man/day routine where work was confined to the mainly daytime hours of $0700-1200$ and 1700-midnight. Figure 1 also reveals that the absolute level of body temperature rose during the course of the 12 days, especially in the two-man/night routine, where it occurred in each of the five Ss, but also in the less arduous routines, so that the effect was significant $(p<.01$, Sign Test) over the whole group of $17 \mathrm{Ss}$.

\section{DISCUSSION}

The two-man system studied here has in almost all respects equalled or surpassed the performance of a conventional arrangement requiring three men to do the same amount of work. This result can be ascribed, presumably, to the two features incorporated in the two-man system, namely the stabilization of daily hours of work and the changing (rotation) of jobs during a given shift. Let us consider which of these two innovations deserves the greater credit.

The argument for stabilizing working hours rests mainly on the claim that those people who have to handle the night shift will be able, gradually, to adapt to working and sleeping at unusual times, provided they do so continuously without returning for odd days to the more normal routine (Kleitman \& Jackson, 1950; van Loon, 1959; Bonjer, 1960). That this happened in the two-man/night routine is suggested by the partial change in the circadian body temperature curve from the first (low level at night) to the last three days (moderately high level at night). It is known that

Table I

Scores in the three performance tests averaged over all Ss in the two systems of manning, 3-man and 2-man (night and day routines combined): (1) The level of performance is shown in each system for the first and last three days. (2) Maintenence of performance during the course of the 12-day promem is shown by an index of change from first to last three days. Means differing at $p<.02$ are shown with * between them, at $\mathrm{p}<.01$ with **

\begin{tabular}{|c|c|c|c|c|c|c|}
\hline & \multicolumn{4}{|c|}{ Level of performance } & \multicolumn{2}{|c|}{$\begin{array}{l}\text { Maintenance of } \\
\text { performance }\end{array}$} \\
\hline & \multicolumn{4}{|c|}{ Average score per 53-min } & \multicolumn{2}{|c|}{$\begin{array}{l}\text { Improvement (t) or } \\
\text { deterioration }(-) \\
\text { in performance from } \\
\text { First to Last } \\
\text { Three days }\end{array}$} \\
\hline & \multicolumn{2}{|c|}{ First 3 days } & \multicolumn{2}{|c|}{ Last 3 days } & \multirow[b]{2}{*}{$2-\operatorname{man}$} & \multirow[b]{2}{*}{ 3-man } \\
\hline & 2-man & 3-man & $2-\operatorname{man}$ & 3-man & & \\
\hline $\begin{array}{l}\text { Vigilance } \\
\text { Signals Detected }\end{array}$ & $10.4 \cdots$ & 8.3 & 11.2 & $* 8.8$ & +0.8 & +0.5 \\
\hline $\begin{array}{l}\text { Adding } \\
\text { Sums Correct }\end{array}$ & 188 & 132 & 261 & 216 & +73 & +84 \\
\hline $\begin{array}{l}\text { Decision-taking } \\
\text { Misses }\end{array}$ & 40.3 & 38.2 & 24.9 & 41.0 & +15.4 & +2.8 \\
\hline Cost (arbitrary units) & $158 *$ & 139 & 170 & 169 & -12 & -30 \\
\hline
\end{tabular}




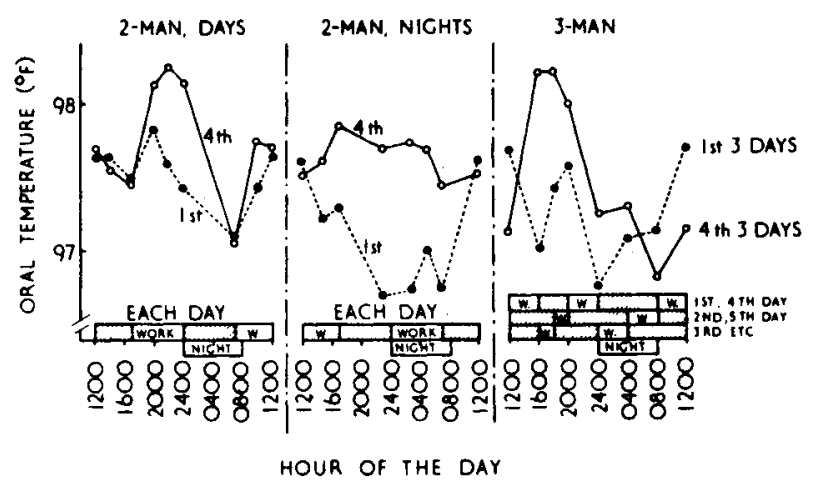

Fig. 1. Twenty-four-h onl temperature patterm averged over first and last 3-days for each routine worked: $3-\mathrm{man}, 2-\mathrm{man} / \mathrm{ni}$ ht , and $2-\mathrm{man} / \mathrm{days}$. Alons the abscisen of each section is shown the distribution of work $(W)$ and off-duty time (shown hatched) over the $24 \mathrm{~h}$ for the routine concerned.

performance level is associated to some extent with body temperature (Kleitman, 1963, p. 152; Colquhoun, Blake, \& Edwards, 1968), and so it follows that by the last three days the two-man system was better attuned to night work than the three-man one in which no such adaptation of body temperature was seen. Accordingly in situations where stabilization of working hours is a significant factor we should expect the maintenance of performance level from first to last three days to be relatively better in the two-man than in the three-man system. This was the case with the Decision-taking but not with Vigilance or Adding.

Any advantage conferred by rotating jobs is due, presumably, to the dissipation of some form of fatigue resulting from repetition of the same or similar operations. Such an advantage we expect to be present in the first shift and to remain relatively unchanged throughout the 12-day program. The score most likely to reflect it therefore is that of overall level of performance. This score, in contrast to that of the maintenance of performance from first to last three days, showed the superiority of the two-man system most in Vigilance and Adding, but not at all in Decision-taking. Indeed during the first three days, when the two-man system might be expected to represent the influence of rotation unalloyed by that of stabilization, Decision-taking was worse in the two-man than in the three-man arrangement.

All this suggests that in Vigilance and perhaps Adding it was the rotation of jobs within the shift which was primarily responsible for the superiority of the two-man system. Decision-taking was impaired by rotation; on the other hand it was the task which benefitted most from stabilization, so that on balance by the last three days it, like Vigilance and Adding, was being carried out at least as efficiently in the proposed two-man system of shifts as in the conventional three-man one.

\section{REFERENCES}

BONJER, F. H. Physiological aspects of thiftwork. Proceeding of the 13th International Congress on Occupational Health, 1960.

COLQHUHOUN, W. P., BLAKE, M. J. K., \& EDWARDS, R. S. Experimentel studies in shift work I: A comperison of "rotating" and "stabilized" 4hour shift systems. Ergonomics, 1968, 11, 437-453.

KLEITMAN, N. Sleep and wakefulnesse 2nd ed., Chicago: University of Chicago Press, 1963.

KLEITMAN, N., JACKSON, D. P. Body temperture and performance under different routines. Journal of Applied Phytiolory, 1950, 3, 309-328.

SHAFFER, L. H. Problem solving on a stochastic process. Engonomics, 1965, $8,181-192$.

van LOON, J. H. The diurnal thythm of body temperature in nipht workers. Acta Physiologica Pharmacologica Neeriandica, 1959, 8.

MLKINSON, R. T. Effects of up to 60 houn of sleep deprivation on different types of work. Ertonomics, 1964, 7, 175-186. NOTE

1. Based on work supported by the Royal Naval Porsonnel Resenrch Committee of the Medical Research Council, United Kingdom. 